\title{
Selenium-Enriched Brushite: A Novel Biomaterial for Potential Use in Bone Tissue Engineering
}

\author{
Aleksandra Laskus ${ }^{1}$, Anna Zgadzaj ${ }^{2}$ and Joanna Kolmas ${ }^{1, *(1)}$ \\ 1 Department of Analytical Chemistry and Biomaterials, Analytical Group, Medical University of Warsaw, \\ ul. Banacha 1, 02-097 Warsaw, Poland; alaskus@wum.edu.pl \\ 2 Department of Environmental Health Sciences, Medical University of Warsaw, ul. Banacha 1, \\ 02-097 Warsaw, Poland; anna.zgadzaj@wum.edu.pl \\ * Correspondence: joanna.kolmas@wum.edu.pl; Tel.: +48-22-572-0755
}

Received: 18 November 2018; Accepted: 11 December 2018; Published: 14 December 2018

\begin{abstract}
In this study, a novel biomaterial, i.e., brushite containing $0.67 \mathrm{wt} \%$ of selenium (Se-Bru) was synthesized via a wet precipitation method. Pure, unsubstituted brushite (Bru) was synthesized via the same method and used as a reference material. Different techniques of instrumental analysis were applied to investigate and compare physicochemical properties of both materials. Fourier-Transform Infrared Spectroscopy confirmed the chemical identity of both materials. Scanning Electron Microscopy (SEM) was used to study the morphology and indicated that both samples (Bru and Se-Bru) consisted of plate-like microcrystals. Powder X-ray Diffraction (PXRD) showed that $\mathrm{Bru}$, as well as Se-Bru were crystallographically homogenous. What is more, the data obtained from PXRD studies revealed that the substitution of selenite ions into the crystal structure of the material had clearly affected its lattice parameters. The incorporation of selenium was also confirmed by solid-state ${ }^{1} \mathrm{H} \rightarrow{ }^{31} \mathrm{P}$ CP MAS kinetics experiments. Additionally, studies on the release kinetics of the elements forming Se-Bru and preliminary cytotoxicity tests were conducted. This preliminary research will favor a better understanding of ionic substitution in calcium phosphates and may be a starting point for the development of selenium-doped brushite cements for potential use in bone tissue impairments treatment.
\end{abstract}

Keywords: selenium; brushite; dicalcium phosphate dihydrate; ionic substitution; biomaterials; bone substitutes

\section{Introduction}

Calcium phosphates $(\mathrm{CaP})$ are widely applied biomaterials in bone tissue and dental surgery. Due to their good bioactivity and biocompatibility, they serve as bone fillers, coating materials and drug delivery system matrices [1]. One of them, dicalcium phosphate dihydrate (DCPD), described with the formula $\mathrm{CaHPO}_{4} \cdot 2 \mathrm{H}_{2} \mathrm{O}$, and known as a mineral brushite, exhibits relatively high solubility [2]. Hydrolyzing easily to octacalcium phosphate and hydroxyapatite, DCPD is considered to be an intermediate phase in bone mineralization and enamel dissolution [3]. Therefore, it is frequently used as a moldable, ready-to-use bone cement and dental coating [3,4].

The solubility of synthesized biomaterial affects the regeneration of mineralized tissue and the release rate of therapeutic agents, i.e., foreign ions or drugs, which may be introduced into the crystal lattice of $\mathrm{CaP}$. Introducing foreign ions involves both cationic and anionic sites of the crystal lattice and is one of the ways of improving different properties of the biomaterials. Not to be groundless, silicon and magnesium are frequently used to enhance the bioactivity of the material [3], zinc and silver improves effectively its antibacterial activity [5], while iron and selenium play a key role as antitumor agents $[6,7]$. 
Being an important constituent of about 25 selenoproteins, selenium takes part in oxidative stress protection and positively affects the immune system and cell proliferation. It is also essential for bone health: a lowered selenium intake may lead to reduced bone turnover and bone mineral density (BMD) $[6,8]$. What is more, a large number of studies has indicated that selenium exhibits a significant anticancer activity. In this field, the form of selenite $\left(\mathrm{SeO}_{3}{ }^{2-}\right)$ was proved to be the most active among all other selenium species [9]. Hydroxyapatite (HA) enriched with selenite ions was found to be a promising material in the treatment of bone tissue metastases and tumors [9-15]. Some studies have also confirmed the antibacterial activity of selenium substituted HA [14,16,17]. Thus, introducing selenium ions into $\mathrm{CaP}$ crystal lattice seems very promising in a view of the development of innovative biomaterials for the treatment of different bone tissue impairments.

To our knowledge, there have been no reports in the literature on DCPD containing selenium. In this work, Se-substituted brushite was synthesized via a standard, wet method. Due to its well-confirmed anticancer potential, the selenite form was chosen as an ionic modifier. Afterwards, the biomaterial was characterized by using the following methods: Powder X-ray Diffractometry (PXRD), Scanning Electron Microscopy (SEM), Infrared Spectroscopy (FT-IR), Inductively Coupled Plasma Mass Spectrometry (ICP-MS) and solid-state Nuclear Magnetic Resonance Spectroscopy (ssNMR). Additionally, the release kinetics of the elements forming Se-Bru and the cytotoxicity of the material were evaluated.

\section{Results and Discussion}

The SEM microphotographs (see Figure 1A,B) revealed that the obtained samples exhibited significantly different morphology. Elongated and plate-like, Bru crystals (Figure 1A) possessed a diameter and length of around 10 and $20-30 \mu \mathrm{m}$, respectively, whereas rod-like Se-Bru crystals (Figure 1B) characterized with a diameter of 5-7 $\mu \mathrm{m}$ and length of more than $25 \mu \mathrm{m}$. Furthermore, in contrast to the Se-Bru sample, the Bru crystals performed stronger tendency to agglomerate.
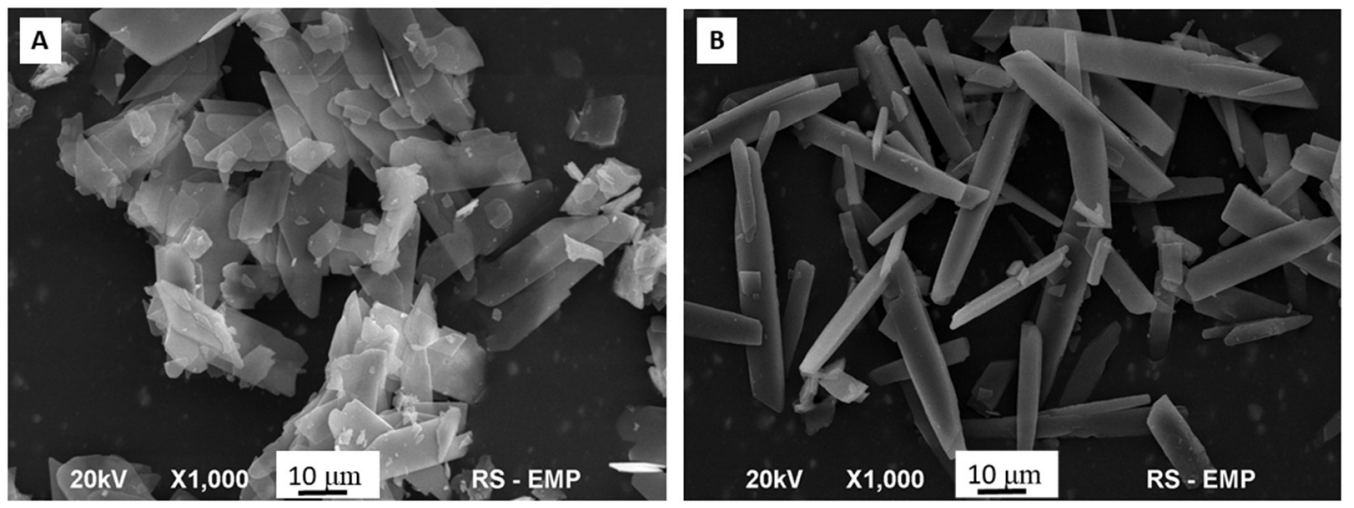

Figure 1. SEM images of Bru (A) and Se-Bru (B).

The diffractograms of both samples are presented in Figure 2. All of the reflections were assigned to the brushite monoclinic structure (JCPDS 09-0077). No other crystalline phase was detected. In case of the Se-Bru sample, a slight reduction of the relative intensity of (020) and (040) reflections was observed. In comparison to pure Bru sample, these reflections varied slightly in position (see Table A1 in Appendix A), which proves that the selenite substitution into the crystal structure of DCPD affected clearly Se-Bru crystallinity and crystal morphology [15]. Additionally, the lattice parameters were calculated (see Table 1). Particularly significant increase of the $a$ parameter, accompanied by the simultaneous decrease of the $c$ parameter in case of the Se-Bru sample, confirms the incorporation of the selenite ions into the crystal structure [18]. 


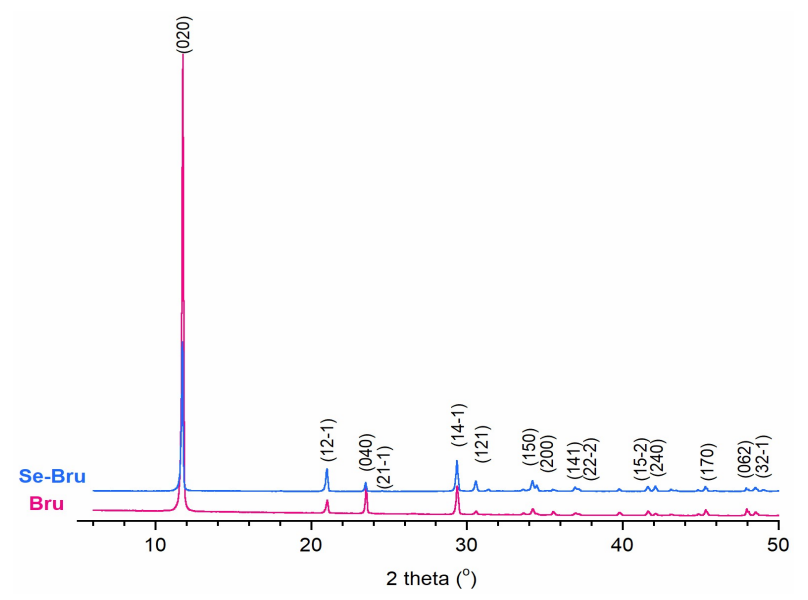

Figure 2. Powder X-ray Diffractometry (PXRD) patterns of Bru and Se-Bru.

Table 1. Various parameters of the obtained materials.

\begin{tabular}{ccc}
\hline Parameters & Bru & Se-Bru \\
\hline Phase Composition & $100 \%$ DCPD & $100 \%$ DCPD \\
Unit Cell Parameters & & \\
$\boldsymbol{a}(\AA)$ & 5.915 & 6.238 \\
$\boldsymbol{b}(\AA)$ & 15.12 & 15.16 \\
$\boldsymbol{c}(\AA)$ & 6.242 & 5.806 \\
$\boldsymbol{\beta}\left({ }^{\circ}\right)$ & 116.4 & 116.4 \\
Volume $\left((\AA)^{\mathbf{3}}\right)$ & 500.2 & 491.7 \\
Se Content $(\mathbf{w t} \%)$ & - & $0.67 \pm 0.03 \%$ \\
\hline
\end{tabular}

The selenium content in the Se-Bru sample was measured by using the ICP-MS method (see Table 1). The concentration of Se amounted to $0.67 \mathrm{wt} \%$.

The FT-IR spectra (see Figure 3A and Table A2 in Appendix B) demonstrated the characteristic bands of dicalcium phosphate dihydrate, as it has been extensively discussed elsewhere $[19,20]$. Briefly, the bands in the regions of $3544-3164 \mathrm{~cm}^{-1}$ and $1649 \mathrm{~cm}^{-1}$ corresponded to the lattice water, stretching and bending vibrations, respectively. The intensive bands in the $1222-790 \mathrm{~cm}^{-1}$ region originated from acidic phosphate groups of DCPD, whereas the band at $661 \mathrm{~cm}^{-1}$ was assigned to the water libration mode. Unfortunately, the selenite bands (at ca. $700-760 \mathrm{~cm}^{-1}$ ) were undetectable [18]. It may be supposed that the selenium content $(0.67 \mathrm{wt} \%)$ was too small to be observed as a visible band in the region of the phosphate bands (a broad intensive band at ca. $790 \mathrm{~cm}^{-1}$, corresponding to the $-\mathrm{POH}$ vibrations).

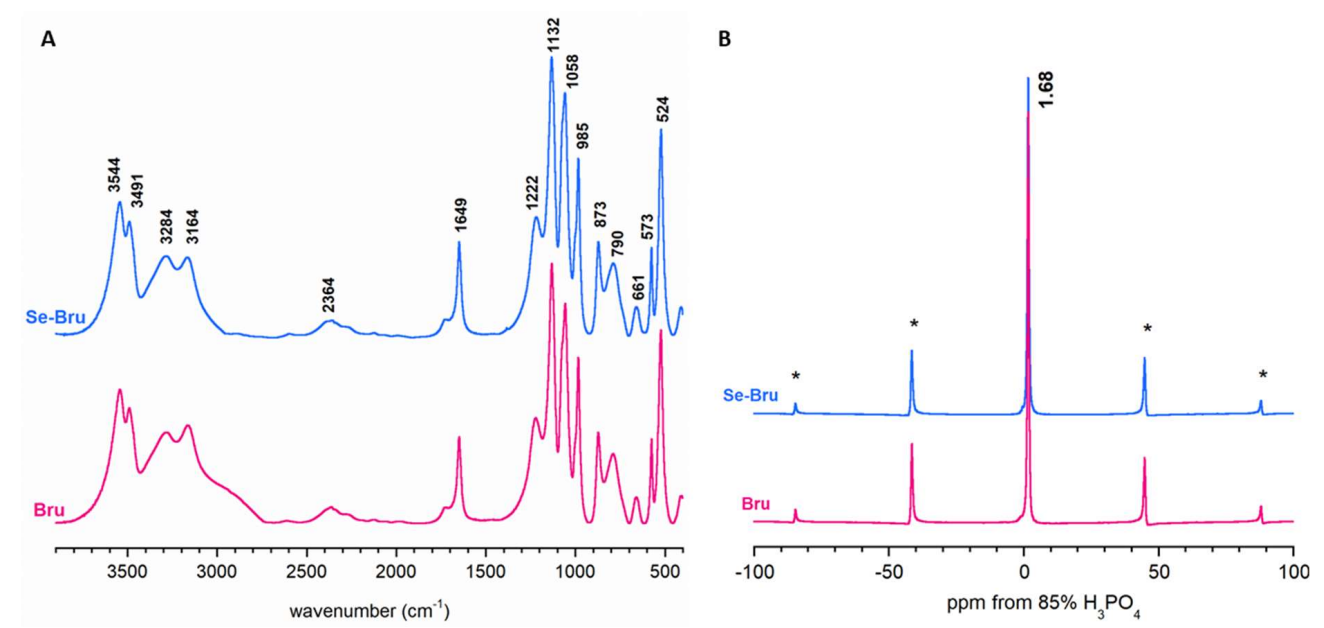

Figure 3. FT-IR (A) and 31P CP MAS NMR (B) spectra of Bru and Se-Bru. The main CP lines are flanked with rotational sidebands (marked with stars). 
The CP MAS NMR spectra of the Bru and Se-Bru samples included one intensive and very narrow signal at about $1.68 \mathrm{ppm}$ flanked by rotational sidebands (see Figure 3B). According to the available literature [21], this can be assigned to ${ }^{31} \mathrm{P}$ nuclei from $\mathrm{HPO}_{4}{ }^{2-}$ groups.

For the signal at ca. $1.68 \mathrm{ppm}$, it was possible to analyze ${ }^{1} \mathrm{H} \rightarrow{ }^{31} \mathrm{P} \mathrm{CP}$ MAS kinetics ( $v_{\mathrm{MAS}}=7 \mathrm{kHz}$ ). To achieve this goal, we studied the dependence of the relative signal intensity (peak area) $\mathrm{I}(t)$ on the contact time $t$ (see Figure 4A,B). The obtained results for both samples, Bru and Se-Bru, followed a non-classical kinetic model corresponding to polarization transfer within clusters of proximate ${ }^{1} \mathrm{H}$ and ${ }^{31} \mathrm{P}$ spins. The experimental points were fitted to a physical function, as follows:

$$
\mathrm{I}(t)=I_{0} \exp \left(-t / T_{1 \rho}^{H}\right)\left[1-\lambda \exp \left(-t / T_{d f}\right)-(1-\lambda) \exp \left(-1.5 t / T_{d f}\right) \exp \left(-0.5 t^{2} / T_{C P^{* 2}}\right)\right]
$$

where: $I_{0}$ is a signal amplitude; $T_{1 \rho}{ }^{H}$ is a proton spin-lattice relaxation time in the rotating frame; $T_{d f}$ is a time constant of proton spin-diffusion; $T_{C P^{*}}$ is a $\mathrm{CP}$ time constant in the non-classical CP model $\left(1 / T_{C P^{*}}\right.$ is the $\mathrm{CP}$ rate), which characterizes the polarization transfer; $\lambda$ is a parameter specific to a cluster of ${ }^{1} \mathrm{H}$ and ${ }^{31} \mathrm{P}$ nuclei involved in initial $\mathrm{CP}$; for a rigid lattice $\lambda=(n+1)^{-1}$, where $\mathrm{n}$ is the number of protons close to the observed ${ }^{31} \mathrm{P}$ nucleus; however, $\lambda$ is dependent on molecular motion, and as such should be treated as an adjustable parameter.
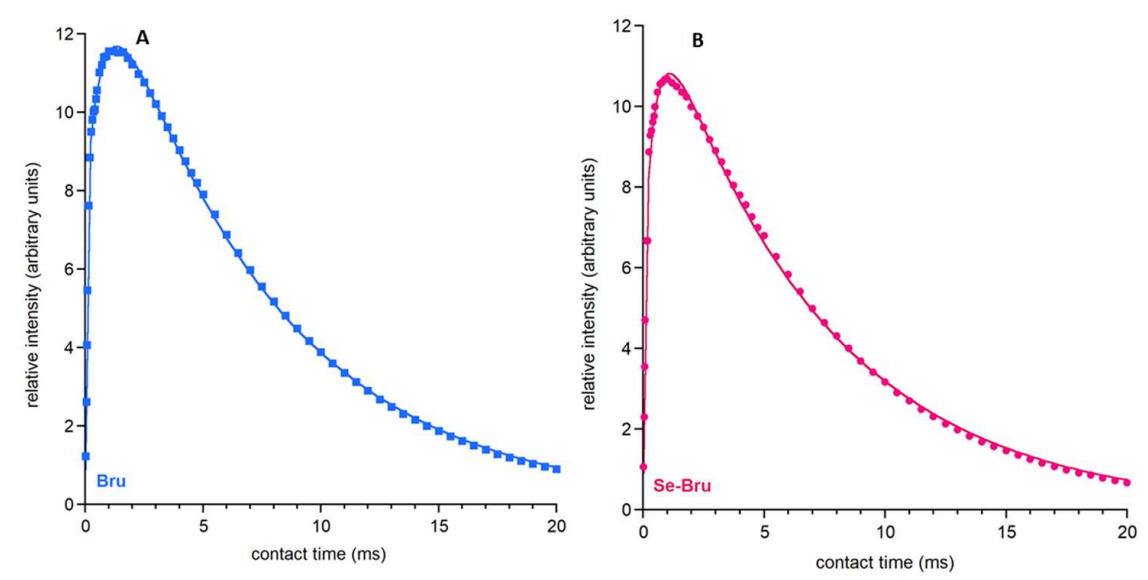

Figure 4. $1 \mathrm{H} \rightarrow 31$ P CP MAS NMR kinetics of the studied materials: Bru (A) and Se-Bru (B).

Our results of $\lambda$ strongly agree with previous research on the ${ }^{1} \mathrm{H} \rightarrow{ }^{31} \mathrm{PCP}$ kinetics of brushite [22]. We can assume that both samples are structurally similar. However, they differ in terms of their $T_{d f}$ and $T_{C P^{*}}$ parameters. $T_{d f}$ is a parameter characterizing ${ }^{1} \mathrm{H}-{ }^{1} \mathrm{H}$ dipolar interactions: the higher its value, the slower the spin diffusion goes between the protons. The $T_{C P^{*}}$ parameter characterizes the dipolar P-H interactions and the polarization transfer: the higher its value, the slower the cross-polarization. Studies of the obtained parameters (see Table 2) have shown that in the Bru sample, the proton spin-diffusion process and cross-polarization are slower than in the Se-Bru sample. This has provided another argument for the changes in the core of the crystal during the substitution of selenite ions.

Table 2. $1 \mathrm{H} \rightarrow 31 \mathrm{P} \mathrm{CP}$ MAS NMR kinetics parameters.

\begin{tabular}{ccc}
\hline Parameters & Bru & Se-Bru \\
\hline $\boldsymbol{T}_{\mathbf{1} \boldsymbol{\rho}}{ }^{\boldsymbol{H}}$ & $7.09 \pm 0.05$ & $6.84 \pm 0.08$ \\
$\lambda$ & $0.51 \pm 0.01$ & $0.54 \pm 0.02$ \\
$\boldsymbol{T}_{d f}$ & $0.88 \pm 0.03$ & $0.56 \pm 0.04$ \\
$\boldsymbol{T}_{\boldsymbol{C} \boldsymbol{P}^{*}}$ & $0.0809 \pm 0.001$ & $0.101 \pm 0.005$ \\
\hline
\end{tabular}

The parameters determined in this experiment (especially $T_{d f}$ and $T_{C P}$ ) showed that the selenite ions partially substituted the acidic phosphates in the brushite crystal structure. 
The investigations of the release kinetics of the ions forming the structure of Se-Bru revealed that the release rate of selenium was significantly higher than the release rate of both calcium and phosphate (see Figure 5). In case of selenium, approximately $43 \%$ of the element introduced into the structure of the material was eluted after four weeks of incubation, while for Ca and $\mathrm{P}$ the level of $10 \%$ of the introduced element was not exceeded. Such a suggestive difference may indicate that the selenite ions might be extensively adsorbed on the surface of brushite crystals. In turn, the low release rate of $\mathrm{Ca}$ and $\mathrm{P}$ may be explained with the slow dissolution rate of investigated $\mathrm{CaP}$ in the applied conditions. Taking into account a well-studied toxicity of selenium particles, such effective elution of selenite ions might be of extreme importance.
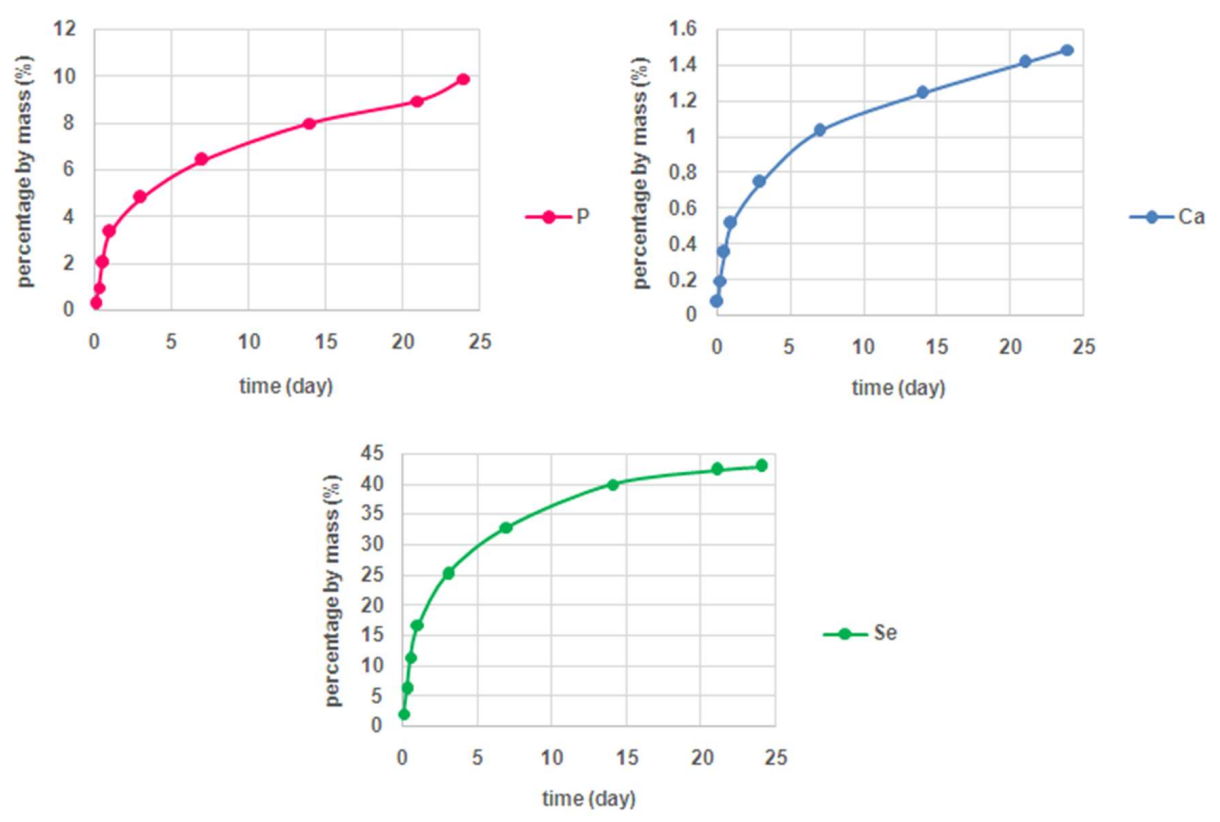

Figure 5. The release kinetics of the elements eluted from Se-Bru.

A probable reason why selenite ions can be partially adsorbed on to the surface of DCPD is the difference in spacial conformation of both $\mathrm{SeO}_{3}{ }^{2-}$ and $\mathrm{PO}_{4}{ }^{3-}$. Although both ions are characterized by a similar ionic radius ( $239 \mathrm{pm}$ for selenite and $238 \mathrm{pm}$ for phosphate), $\mathrm{PO}_{4}{ }^{3-}$ ions are tetrahedral, while $\mathrm{SeO}_{3}{ }^{2-}$ ions are of a flat trigonal pyramid conformation [22].

The results of the cytotoxicity tests correspond clearly with the release kinetics of selenium. Due to the high level of selenium eluted from the material, Se-Bru turned out to be more toxic $\left(\mathrm{IC}_{50}=\right.$ $27 \mathrm{mg} / \mathrm{mL}$ ) than the pure brushite (see Figure 6). The extract prepared with Bru was nontoxic for the cells within the whole range of dilutions, whereas the toxicity of the extract prepared with Se-Bru decreased substantially with the increase of dilution fold. This tendency may be a starting point for creating nontoxic, therapeutic CaP, modified with selenium particles. On the other hand, such activity may be of great importance in treating bone tumors. Se-DCPD could also be applied as a component of matrices for anticancer drugs targeting bones or as a filler for bone defects caused by bone tumor removal.

Studies on doping Se into the crystal structure of $\mathrm{CaP}$ began in 2014 and are still being conduted. Due to the triple activity of selenium particles (osteoconductive, anticancer and antibacterial) [11-14,17,23-27], introducing Se into $\mathrm{CaP}$ materials seems to be a very promising direction for bone tissue engineering. Although there have been reports on doping selenium into the crystal structure of HA [11-14,17,18,23-27], there has been no similar approach to synthesize selenium-modified DCPD. The possibility to introduce Se into its crystal structure has never been verified, although there are studies on doping various ions into the crystal lattice of DCPD [28-30]. In the studies mentioned above, Se-HA exhibited content-dependent, osteoconductive, and anticancer activity $[11,13,14]$. In some of them $[14,17]$, selenium also acted as an 
antibacterial agent. The anticancer activity of selenium was proved to be based on the mechanism of apoptosis of cancer cells [11,13].

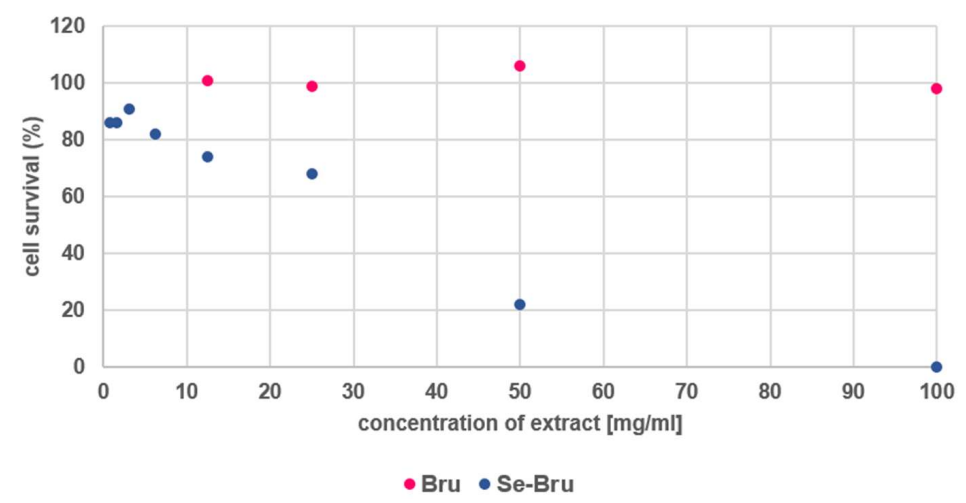

Figure 6. Survival of the cells after the exposition.

Hydroxyapatite is known to be the least soluble material among CaP [1]. In turn, DCPD belongs to a group of $\mathrm{CaP}$, which is far more soluble than HA [1]. Due to its low solubility, bone-grafting using HA sometimes involves leaving the graft remnant in the affected area; it could lead to limited bioavailability of $\mathrm{Ca}$ and $\mathrm{P}$ for bone cells.

DCPD is most commonly used as a moldable, hydraulic bone cement with a higher surgical handiness in comparison to HA [1,31]. In addition, its solubility may improve the bioavailability of the $\mathrm{Ca}, \mathrm{P}$ and other introduced, therapeutic ions, which gives it a significant advantage over HA-based, traditional biomaterials.

To briefly sum up, in comparison to the existing landscape of biomaterials, selenium-doped DCPD offers a few advantages. First, it confirms the possibility to introduce a promising agent (Se) into the crystal structure of DCPD. Second, Se-DCPD with a well-confirmed toxicity could be applied as a component of handy bone cements or matrices for anticancer drugs targeting bones, playing therefore, a synergistic role in treating bone cancer. Third, cytotoxicity tests provide important information for future investigations in this field; for example, focusing on its osteoconductive properties, the amount of introduced selenium should be below $0,67 \mathrm{wt} \%$ in order to obtain non-toxic material.

\section{Materials and Methods}

\subsection{Sample Preparation}

Samples were prepared by using a standard, wet precipitation method. The sources of calcium $\left(\mathrm{Ca}\left(\mathrm{NO}_{3}\right)_{2} \cdot 4 \mathrm{H}_{2} \mathrm{O}\right)$, phosphorus $\left(\left(\mathrm{NH}_{4}\right)_{2} \mathrm{HPO}\right)$, and selenium $\left(\mathrm{Na}_{2} \mathrm{SeO}_{3}\right)$ were all purchased from Sigma-Aldrich, Poznań, Poland. To synthesize brushite containing selenium (Se-Bru) the reagents were weighed out so that the molar ratios of $\mathrm{Ca} / \mathrm{P}+\mathrm{Se}$ and $\mathrm{P} / \mathrm{Se}$ were close to 1.0 and 1.5 , respectively. Afterwards, all of them were dissolved in distilled water. The water solution of both phosphate and selenite were added dropwise to the solution of calcium. The precipitation process was carried under continuous stirring. Once the $\mathrm{pH}$ was adjusted to about 6 , the intensive stirring was continued for one hour. The precipitate was left for $24 \mathrm{~h}$ to age, then filtered and washed out several times with distilled water. Subsequently, the precipitate was dried at the temperature of $90{ }^{\circ} \mathrm{C}$ for $24 \mathrm{~h}$. The route of the synthesis of pure brushite (Bru) was hardly any different: the reagents lacked in selenium source and were weighed out so that the $\mathrm{Ca} / \mathrm{P}$ ratio was about 1.0.

\subsection{Characterization}

The dried powders were homogenized in mortar and characterized by using the following methods: 
To determine the morphology of the crystals, SEM microscopy (JSM-6390LV JEOL microscope, JEOL LTD, Tokyo, Japan) was applied. Prior to the measurements, the samples had been covered with an Au layer.

The phase composition was analyzed by using the PXRD method (Bruker DX8 Discover diffractometer with $\mathrm{CuK} \alpha$ radiation, Bruker, Madison, WI, US). The lattice parameters: $a, b, c$, and $\beta$ angle of the unit cell, as well as the cell unit volumes were obtained from the TOPAS program (Bruker).

The presence of functional groups was determined by FT-IR spectra (Perkin Elmer Spectrum 1000 spectrometer Waltham, MA, US) recorded by using the transmission technique of the KBr tablet with a spectral range of 4000 to $400 \mathrm{~cm}^{-1}$.

Selenium content was measured by using ICP-MS spectrometry (Optima 3100XL, Perkin Elmer). Samples had previously been dissolved in $\mathrm{HNO}_{3}$ and diluted properly with deionized water.

High-resolution ssNMR spectra (Bruker Avance 400 WB spectrometer, Bruker) were collected at 298 K, operating at $9.4 \mathrm{~T}$. The ${ }^{31} \mathrm{P}$ cross-polarization $(\mathrm{CP})$ experiments were performed in a $4-\mathrm{mm}$ probe under magic angle spinning (MAS) at $7 \mathrm{kHz}$. For single CP experiments, $2.65 \mu \mathrm{s}$ of $\pi / 2$ pulse, a $10 \mathrm{~s}$ recycle delay, $2 \mathrm{~ms}$ of contact time and 32 scans were applied. The variable contact time ${ }^{1} \mathrm{H} \rightarrow{ }^{31} \mathrm{P} C \mathrm{CP}$ MAS NMR experiments were performed for 64 arrayed contact time values from $25 \mu \mathrm{s}$ to $20 \mathrm{~ms}$. The relative signal intensities were calculated using the NUTS NMR program, according to a line-fitting process. The CP kinetic functions were fitted with the KaleidaGraph 3.5, Synergy Software, Synergy, Reading, PA, USA).

The release rate of all three elements ( $\mathrm{Ca}, \mathrm{P}$ and $\mathrm{Se}$ ) eluted from Se-Bru after different periods of time was determined in the phosphate buffer solution $(\mathrm{pH}=7,4)$ at $37^{\circ} \mathrm{C}$. Approximately $1 \mathrm{~g}$ of Se-Bru powder was suspended in $12 \mathrm{~mL}$ of the buffer and then subjected to shaking. Subsequently, samples of $8 \mathrm{~mL}$ volume were collected and further investigated. The concentration of each element was measured after 1, 6, 12, 24, $72 \mathrm{~h}$, and after 1, 2, 3, and 4 weeks. All measurements were performed by inductively coupled plasma optical emission spectroscopy (ICP-OES), (iCAP 7000 spectrometer, Thermo Scientific Waltham, MA, US) and done in triplicate.

In order to evaluate cytotoxicity of Bru and Se-Bru samples, the neutral red uptake test was performed on the basis of ISO 10993 guideline Annex A1 with BALB/c 3T3 clone A31 mammalian cell line. The quantitative estimation of viable cells in tested culture was based on their neutral red uptake in comparison to the results obtained for untreated cells. Dead cells have no ability to accumulate the dye in their lysosomes. The BALB/c 3T3 cells were seeded in 96-well microplates $\left(10^{4}\right.$ cells $/ 100$ $\mu \mathrm{L}$ ) in DMEM (Lonza, Basel, Switzerland) culture medium and incubated for $24 \mathrm{~h}$. At the end of the incubation, each well was examined under a microscope to ensure that cells form a half-confluent monolayer. Subsequently, culture medium was replaced by the tested extracts. Extracts were prepared by incubation of tested materials (Bru and Se-Bru) in the cell culture medium $(100 \mathrm{mg} / \mathrm{mL}$ ) with reduced serum concentration $(5 \%)$ at $37^{\circ} \mathrm{C}$ for $24 \mathrm{~h}$. The cells were treated with at least four dilutions of each extract in a twofold dilution series for $24 \mathrm{~h}$. Subsequently treatment medium was removed. The cells were washed with PBS and treated with the neutral red medium for $2 \mathrm{~h}$. Afterwards, the medium was discarded, and the cells were washed with PBS and treated with desorbing fixative (ethanol and acetic acid water solution). The amount of neutral red accumulated by cells were evaluated colorimetrically at $540 \mathrm{~nm}$. Polyethylene foil and latex were used as negative and positive controls, respectively. The percentage of viable cells in each well was calculated by comparing its $\mathrm{OD}_{540}$ result with the mean result obtained for untreated cells (incubated in the same conditions with fresh culture medium).

\section{Conclusions}

In this study, brushite crystals were modified with selenite ions. The synthesized DCPD contained $0.67 \mathrm{wt} \%$ of selenium and simultaneously exhibited a rod-like microcrystal morphology. The physicochemical methods confirmed the introduction of Se into the DCPD crystal structure. Despite this fact, the evaluation of the release kinetics of the elements forming Se-Bru revealed that the selenium particles might be also extensively concentrated on the surface of DCPD, which in turn may 
be responsible for its high toxicity. The cytotoxicity tests might be a starting point for creating nontoxic, but therapeutic CaP modified with selenium particles. Nonetheless, the toxicity of the synthesized material could be of significant importance in view of its killing effect towards osteosarcoma cells.

Author Contributions: A.L. participated in the synthesis and physicochemical analysis of the samples and wrote the manuscript. J.K. provided the concept of the work, interpreted the results, and helped in the NMR analysis. A.Z. was responsible for cytotoxicity test. All authors have contributed to and approved the manuscript.

Funding: This work was supported by the research programme (UMO-2016/22/E/ST5/00564) of the National Science Center, Poland.

Acknowledgments: The authors are grateful to Dr. Lukasz Szeleszczuk for his help during PXRD data analysis and to the Polish Centre of Technological Development in Wroclaw for the possibility to conduct the studies on the release kinetics of elements.

Conflicts of Interest: The authors declare no conflict of interest.

\section{Appendix A}

Table A1. Peak positions in PXRD diffractograms for the Bru and Se-Bru samples.

\begin{tabular}{ccc}
\hline & \multicolumn{2}{c}{ Peak Position-2 Theta $\left(^{\circ}\right)$} \\
\hline Peak Index & Bru & Se-Bru \\
$\mathbf{0 2 0}$ & $\mathbf{1 1 . 7 5}$ & $\mathbf{1 1 . 7 0}$ \\
$\mathbf{1 2 - 1}$ & 21.00 & 20.99 \\
$\mathbf{0 4 0}$ & 23.50 & 23.47 \\
$\mathbf{2 1 - 1}$ & 24.56 & 24.53 \\
$\mathbf{1 4 - 1}$ & 29.35 & 29.33 \\
$\mathbf{1 2 1}$ & 30.56 & 30.54 \\
$\mathbf{1 5 0}$ & 34.19 & 34.18 \\
$\mathbf{2 0 0}$ & 34.45 & 34.45 \\
$\mathbf{1 4 1}$ & 37.06 & $\mathbf{3 6 . 9 0}$ \\
$\mathbf{2 2 - 2}$ & 37.17 & 37.14 \\
$\mathbf{1 5 - 2}$ & 41.61 & 41.60 \\
$\mathbf{2 4 0}$ & 42.09 & 42.08 \\
$\mathbf{1 7 0}$ & 45.30 & 45.27 \\
$\mathbf{0 6 2}$ & 47.95 & 47.92 \\
$\mathbf{3 2 - 1}$ & 48.61 & 48.60 \\
\hline
\end{tabular}

\section{Appendix B}

Table A2. Infrared bands $\left(\mathrm{cm}^{-1}\right)$ for the Bru and Se-Bru samples and their assignments [14].

\begin{tabular}{ccc}
\hline \multicolumn{2}{c}{ Wavenumbers (CM-1) } & Vibration Modes \\
\hline Bru & Se-Bru & \\
$3544-3491$ & $3544-3491$ & $v_{3} \mathrm{H}_{2} \mathrm{O}$ (lattice water molecules) \\
$3283-3163$ & $3285-3167$ & $v_{1} \mathrm{H}_{2} \mathrm{O}$ (lattice water molecules) \\
2943 & 2945 & PO-H stretching \\
2364 & 2359 & Combination (bending) and rotation of residual free water \\
1725 & 1727 & $\mathrm{H}-\mathrm{O}-\mathrm{H}$ bending of lattice water molecules \\
1649 & 1650 & $\delta(\mathrm{PO}-\mathrm{H})$ \\
1222 & 1219 & $v_{\mathrm{d}}(\mathrm{P}-\mathrm{OH})$ \\
1133 & 1134 & $v_{\mathrm{s}}(\mathrm{P}-\mathrm{OH})$ \\
1058 & 1060 & $\nu(\mathrm{P}-\mathrm{O}(\mathrm{H}))$ \\
985 & 985 & $\delta(\mathrm{P}-\mathrm{O}(\mathrm{H}))$ \\
874 & 873 & water libration \\
790 & 790 & $\delta(\mathrm{O}-\mathrm{P}-\mathrm{O}(\mathrm{H}))$ \\
660 & 660 & $\delta(\mathrm{O}-\mathrm{P}-\mathrm{O}(\mathrm{H}))$ \\
576 & 577 & $\delta(\mathrm{O}-\mathrm{P}-\mathrm{O}(\mathrm{H}))$ \\
524 & 523 & \\
410 & 412 &
\end{tabular}




\section{References}

1. Dorozhkin, S.V. Calcium Orthophosphates in Nature, Biology and Medicine. Materials 2009, 2, 399-498. [CrossRef]

2. Mandel, S.; Tas, A.C. Brushite $\left(\mathrm{CaHPO}_{4} \cdot 2 \mathrm{H}_{2} \mathrm{O}\right)$ to octacalcium phosphate $\left(\mathrm{Ca}_{8}\left(\mathrm{HPO}_{4}\right)_{2}\left(\mathrm{PO}_{4}\right)_{4} \cdot 5 \mathrm{H}_{2} \mathrm{O}\right)$ transformation in DMEM solution at $36.5^{\circ} \mathrm{C}$. Mater. Sci. Eng. C 2010, 30, 245-254. [CrossRef] [PubMed]

3. Boanini, E.; Ganzano, M.; Bigi, A. Ionic substitutions in calcium phosphates synthesized at low temperature. Acta Biomater. 2010, 6, 1882-1894. [CrossRef] [PubMed]

4. Lee, D.W.; Shin, M.C.; Kim, Y.N.; Oh, J.M. Brushite ceramics coatings for dental brace brackets fabricated via aerosol deposition. Ceram. Int. 2017, 43, 1044-1051. [CrossRef]

5. Kolmas, J.; Groszyk, E.; Kwiatkowska-Różycka, D. Substituted Hydroxyapatites with Antibacterial Properties. Biomed. Res. Int. 2014, 2014, 1-15. [CrossRef] [PubMed]

6. Rayman, M.P. The importance of Selenium to Human Health. Lancet 2000, 356, 233-241. [CrossRef]

7. Rayman, M.P. Selenium in cancer prevention: A review of the evidence and mechanism of action. Proc. Nutr. Soc. 2005, 64, 527-542. [CrossRef]

8. Zeng, H.; Cao, J.J.; Combs, G.F., Jr. Selenium in Bone Health: Roles in Antioxidant Protection and Cell Proliferation. Nutrients 2013, 5, 97-110. [CrossRef]

9. Fernandes, A.P.; Gandin, V. Selenium compounds as therapeutic agents in cancer. Biochim. Biophys. Acta 2015, 1850, 1642-1660. [CrossRef]

10. Blackburn, G.; Scott, T.G.; Bayer, I.S. Bionanomaterials for bone tumor engineering and tumor destruction. J. Mater. Chem. B 2013, 1, 1519. [CrossRef]

11. Wang, Y.; Ma, J.; Zhou, L.; Chen, J.; Liu, Y.; Qiu, Z.; Zhang, S. Dual functional selenium-substituted hydroxyapatite. Interface Focus 2012, 2, 378-386. [CrossRef] [PubMed]

12. Wang, Y.; Hang, H.; Yan, L.; Zhang, S. Selenium-substituted hydroxyapatite nanoparticles and their in vivo antitumor effect on hepatocellular carcinoma. Colloids Surf. B Biointerfaces 2016, 140, 297-306.

13. Wang, Y.; Wang, J.; Hao, H.; Cai, M.; Wang, S.; Ma, J.; Li, Y.; Mao, C.; Zhang, S. In Vitro and In Vivo Mechanism of Bone Tumor Inhibition by Selenium-Doped Bone Mineral Nanoparticles. ACS Nano. 2018, 10, 9927-9937. [CrossRef] [PubMed]

14. Uskokovic, V.; Iyer, M.A.; Wu, V.M. One Ion to Rule Them All: Combined Antibacterial, Osteoinductive and Anticancer Properties of Selenite-Incorporated Hydroxyapatite. J. Mater. Chem. B 2017, 5, 1430-1445. [CrossRef] [PubMed]

15. Zhang, W.; Chai, Y.; Cao, N.; Wang, Y. Synthesis and characterization of selenium substituted hydroxyapatite via hydrothermal method. Mater. Lett. 2014, 134, 123-125. [CrossRef]

16. Kolmas, J.; Groszyk, E.; Piotrowska, U. Nanocrystalline hydroxyapatite enriched in selenite and manganese ions: Physicochemical and antibacterial properties. Nanoscale Res. Lett. 2015, 10, 278. [CrossRef] [PubMed]

17. Yilmaz, B. Surface Characterization and Biocompatibility of Selenium-Doped Hydroxyapatite Coating on Titanium Alloy. Int. J. Appl. Ceram. Technol. 2016, 13, 1059-1068. [CrossRef]

18. Kolmas, J.; Oledzka, E.; Sobczak, M.; Nałęcz-Jawecki, G. Nanocrystalline hydroxyapatite doped with selenium oxyanions: A new material for potential biomedical applications. Mater. Sci. Eng. C 2014, 39, 134-142. [CrossRef]

19. Trpkovska, M.; Soptrajanov, B.; Malkov, P. FTIR reinvestigation of the spectra of synthetic brushite and its partially deuterated analogues. J. Mol. Struct. 1999, 480-481, 661-666. [CrossRef]

20. Rey, C.; Marsan, O.; Combes, C.; Drouet, C.; Grossin, D.; Sarda, S. Characterization of Calcium Phosphates using vibrational spectroscopies. In Advances in Calcium Phosphate Biomaterials; Ben-Nissan, B., Ed.; Springer: Berlin/Heidelberg, Germany, 2014; pp. 229-267.

21. Kaflak-Hachulska, A.; Slosarczyk, A.; Kolodziejski, W. Kinetics of NMR cross-polarization from protons to phosphorus-31 in natural brushite. Solid State Nucl. Magn. Reson. 2000, 15, 237-238. [CrossRef]

22. Pajor, K.; Pajchel, L.; Kolodziejska, B.; Kolmas, J. Selenium-Doped Hydroxyapatite Nanocrystals-Synthesis, Physicochemical Properties and Biological Significance. Crystals 2018, 8, 188. [CrossRef]

23. Wang, Y.; Lv, P.; Ma, Z.; Zhang, J. Enhanced Healing of Rat Calvarial Critical Size Defect with Selenium-Doped Lamellar Biocomposites. Biol. Trace Elem. Res. 2013, 155, 72-81. [CrossRef] [PubMed] 
24. Sun, J.; Zheng, X.; Li, H.; Fan, D.; Song, Z.; Ma, H.; Hua, X.; Hui, J. Monodisperse selenium-substituted hydroxyapatite: Controllable synthesis and biocompatibility. Mat. Sci. Eng. C 2017, 73, 596-602. [CrossRef] [PubMed]

25. Wang, Y.; Hang, H.; Zhang, S. Biomimetic Coprecipitation of Silk Fibrin and Calcium Phosphate: Influence of Selenite Ions. Biol. Trace Elem. Res. 2017, 178, 338-347. [CrossRef]

26. Hemalatha, T.; Krithiga, G.; Kumar, B.S. Preparation and Characterization of Hydroxyapatite-Coated Selenium Nanoparticles and their Interaction with Osteosarcoma $\left(\mathrm{SaOS}^{-2}\right)$ Cells. Acta Metall. Sin. (Engl. Lett.) 2014, 27, 1152-1158. [CrossRef]

27. Wei, 1.; Yang, H.; Hong, J.; He, Z.; Deng, C. Synthesis and structure properties of Se and Sr codoped hydroxyapatite and their biocompatibility. J. Mater Sci. 2019, 54, 2514-2525. [CrossRef]

28. Guerra-Lopez, J.R.; Guida, J.A.; Ramos, M.A.; Punte, G. The influence of Ni(II) on brushite structure stabilization. J. Mol. Str. 2017, 720-724. [CrossRef]

29. Cabrejos-Azama, J.; Alkhraisat, M.H.; Rueda, C.; Torres, J.; Pintado, C.; Blanco, L.; \& López-Cabarcos, E. Magnesium substitution in brushite cements: Efficacy of a new biomaterial loaded with vancomycin for the treatment of Staphylococcus aureus infections. Mat. Sci. Eng. C 2016, 61, 72-78. [CrossRef]

30. Cummings, H.; Han, W.; Vahabzadeh, S.; Elsawa, S.F. Cobalt-Doped Brushite Cement: Preparation, Characterization, and In Vitro Interaction with Osteosarcoma Cells. JOM 2017, 69, 1348-1353. [CrossRef]

31. Tamimi, F.; Sheikh, Z.; Barralet, J. Dicalcium phosphate cements: Brushite and monetite. Acta Biomater. 2012, 8, 474-487. [CrossRef]

(C) 2018 by the authors. Licensee MDPI, Basel, Switzerland. This article is an open access article distributed under the terms and conditions of the Creative Commons Attribution (CC BY) license (http:/ / creativecommons.org/licenses/by/4.0/). 